\title{
Le viol de Tarquin - Ophélie - « Unsex me here »
}

Jacques Jouet

\section{(2) OpenEdition \\ Journals}

\section{Édition électronique}

URL : http://journals.openedition.org/shakespeare/1917

DOI : 10.4000/shakespeare.1917

ISSN : 2271-6424

Éditeur

Société Française Shakespeare

\section{Édition imprimée}

Date de publication : 1 avril 2013

Pagination : 255-258

ISBN : 2-9521475-9-0

\section{Référence électronique}

Jacques Jouet, «Le viol de Tarquin - Ophélie - « Unsex me here » », Actes des congrès de la Société française Shakespeare [En ligne], 30 | 2013, mis en ligne le 03 avril 2013, consulté le 22 avril 2019. URL: http://journals.openedition.org/shakespeare/1917 ; DOI : 10.4000/shakespeare.1917 


\section{Shakespeare et la mémoire}

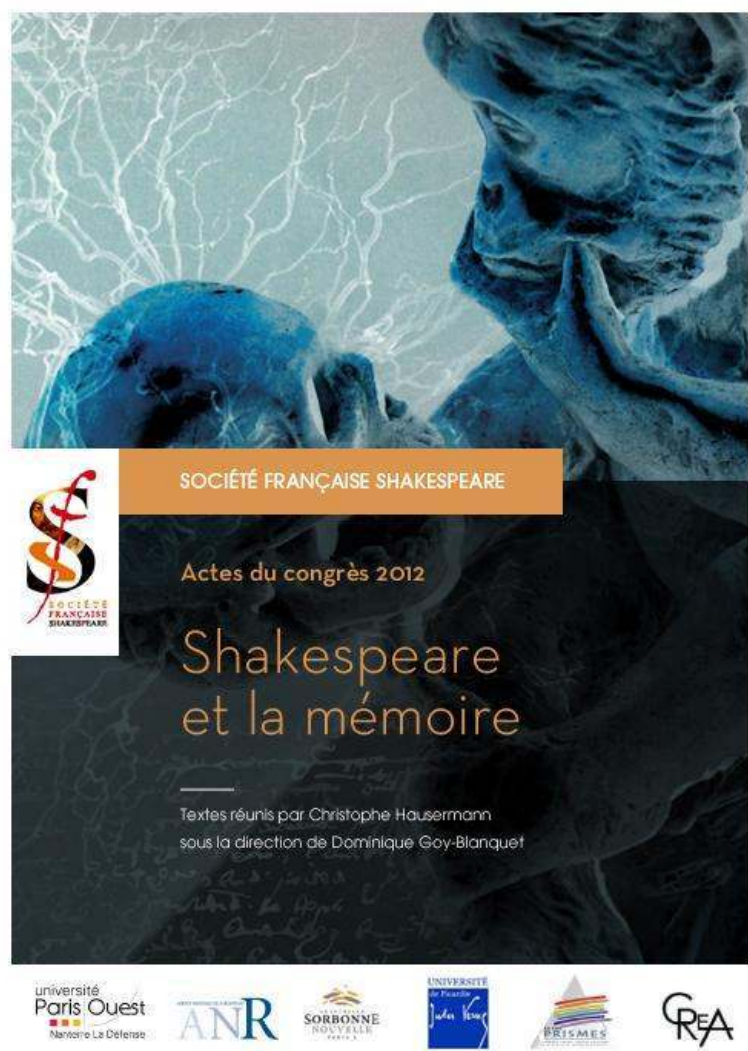

actes du Congrès

organisé par la

SOCIÉTÉ FRANÇAISE SHAKESPEARE

les 22, 23 et 24 mars 2012

textes réunis par

Christophe HAUSERMANN

sous la direction de

Dominique GoY-BLANQUET 


\section{COUVERTURE}

d'après l'affiche de Claire Colombet

conception graphique et logo

Pierre Kapitaniak

mise en page et corrections

Christophe Hausermann

(C) 2012 Société Française Shakespeare

Institut du Monde Anglophone

Université de Paris III - Sorbonne Nouvelle

5 rue de l'École de Médecine 75006 Paris

www.societefrancaiseshakespeare.org

Tous droits de traduction, de reproduction et d'adaptation réservés pour tous les pays 


\title{
LE VIOL DE TARQUIN
}

\author{
Jacques Jouet
}

Façons de traiter le complément de nom dis-moi si tu veux que le viol appartienne à Tarquin se risquant instinctif, et non à Lucrèce (que nature et choses viennent librement, mais avec interposition de ce qui se fut appelé les Lumières). Le viol peut-il appartenir à l'action postérieure de celle qui fut sévèrement de toute appartenance volée ? Ah ! le couteau alors est révolutionnaire pas que personnel intime et tout seul, pas pourrissable, pas jetable avec ses glaires. L'orchidée aura été la fleur maudite pour de bonnes raisons étymologiques.

Après qu'il a ouvert avec le genou la porte de ce qu'il croit n'être que chambre Tarquin la non colombe à savoir hibou s'engage tout entier, tiré par son membre. Il ne sait pas encore que les deux seins de Lucrèce sont aussi gros que deux mondes que son corps endormi, les ventre et bassin sont une ville aux maisons de pierres blondes et que prendre, ainsi qu'il va, ce pauvre corps est un coup d'État par assassinat, crime conquête de sauvagerie à tous torts de son côté, salissure qui ne rime qu'avec le viol de soi-même et déraison avec la mort qu'on fait entrer dans sa maison. 
C'est donc l'intime qui est chose publique comme rien d'autre ne peut l'être à ce point devant un nom de dynastie tyrannique Tarquin, du Superbe ${ }^{*}$ à qui ne l'est pas moins. La chute, la déconfiture est morale * Superbus : orgueilleux, avant la version manu militari.

Si le cas vient qu'une citoyenne râle le pouvoir est instantanément pourri.

Tarquin sait qu'il se viole, il se viole encore il se viande, il se perd, il se jette aux chiens il se trahit, se vomit, il s'expectore ou pire il se sait par là fidèle aux siens. Enfin Lucrèce a retrouvé le sourire dans la non-tombe des livres qu'on peut lire. hautain

Sources : Ovide Les Fastes. - Tite-Live Histoire romaine, I, traduit par M. Nisard. - Shakespeare The Rape of Lucrece, 1594. - Benjamin Britten The Rape of Lucretia, opéra, livret de Ronald Duncan, 1946, d'après la pièce d'André Obey Le Viol de Lucrèce, 1931. 
OPHelie

Tu fais peur, Ophélie, tu fais peur tu ne peux pas savoir comme tu me fais peur à te trucider d'eau et te tuicider.

La distribution des fleurs, tous les Hamlet que j'ai vus je ne supporte pas cette scène.

Tu me fais peur, Ophélie, tu fais peur ou c'est Hamlet en moi qui me fait peur un Hamlet insidieux, injuste, assombrisseur auquel je ne veux pas ressembler. Tu m'angoisses, Ophélie, tu me fais très très peur poussée par toi-même plus loin que l'admissible de soi-même.

Heureusement qu'il y a Catherine actrice toute jeune et qui joua le cadavre que du rôle la tenancière refusait d'assumer.

Catherine naît au théâtre par le rôle muet de ce légume faisandé. Et cette Ophélie-là qui entretient la vie du personnage, alors je l'aime alors elles ne me font pas peur. 
258 JACQUES JOUET

« UNSEX ME HERE 》

Lady Macbeth à l'acte I, scène cinquième demande à ses esprits de mortelles pensées le bon débarras de ce sexe qu'on aime en un mot, traduit Déprats, de la « désexuer » qu'on aime pour sa supposée sainte faiblesse ou la vocation ancrée de la protection du vivant, savoir de l'enfant que rien ne blesse ou blessera. Lady Macbeth a l'intention de découper plus qu'un de ses seins d'amazone le bazar, bataclan, l'attirail, «faites-moi sans mon sexe », traduit Pierre-Jean Jouve. Jaune est son rire bilieux, c'est ainsi, c'est la loi le lait même écrémé sera devenu fiel le fiel au grand jamais ne redeviendra miel.

Source : Shakespeare, Macbeth, traductions diverses. 